\title{
Supply Chain Risk Management for the SME's
}

\author{
Sabariah Yaakub \\ Hamidatun Khusna Mustafa
}

\section{Doi:10.5901/ajis.2015.v4n1s2p151}

\section{Abstract}

Small and Medium Enterprises (SMEs) are a vital component in economic development and bring benefits to the country as they provide employment, increase income, and foster economic growth. However, SMEs have many shortcomings including small size, short capital, and reliance on support from the government. In addition, SMEs are usually companies that are less structured, with small management group, inadequately organised, as well as having informal risk management structure. This study argues for the benefit of adopting SCRM in Malaysian SME. Supply chain risk management (SCRM) focuses on supply chain risk phenomena and provides models for the analysis of several types of supply chain risks that occur in both supply and demand sides of the supply chains. The purpose of SCRM is to recognise the potential supply chain uncertainties and prevent the uncertainties with appropriate action. SCRM is made of four basic categories; risk sources, risk consequences, risk drivers, and risk mitigation strategies. This study focuses on risk mitigation strategies that should be implemented by SME to overcome challenges that they faced. The main problem is that there is lack of knowledge in the application of SCM, especially SCRM in the context of SMEs. In fact, there are still plenty of companies that have not establish a structured supply chain risk management and mitigation system and unaware of supply chain disruption risk management. Therefore, this study seeks to examine risk mitigation strategies and their effect on the company's performance in Malaysian SME's. Data was collected through survey questionnaire and the respondents consist of SMEs located in Malaysia. Data analysis was conducted using SPSS and findings indicate that there is significant relationship between risk mitigation strategies adopted by the SMEs and their company performance.

Keywords: Supply Chain Risk Management, Small and Medium Enterprise, Supply Chain Management

\section{Introduction}

Small medium enterprise (SME) represents $99.2 \%$ (645,136 companies) of the total business established in Malaysia (National SME Development Council, 2012; Department of Statistics Malaysia, 2011). Both developing and developed countries around the world viewed SME as a vital component in economic development (Hashim, 2011). In addition, SMEs bring benefits to the country as they provide employment, increase income, and foster economic growth (National SME Development Council, 2012).

However, SMEs have many shortcomings including small size, short capital, and reliance on support from the government. Besides, National SME Development Council (2012) has listed several challenges that prevent them from achieving high performance. According to Lavastre, Gunasekaran and Spalanzani (2012), they define SME as a company that is less structured, having small management group and inadequately organised, as well as informal of risk management. Because of that, this study will argue the benefit of adopting SCRM in Malaysian SME.

Supply chain risk management (SCRM) focuses on supply chain risk phenomena and provides models for the analysis of several types of supply chain risks that occur in both supply and demand sides of the supply chains. The purpose of SCRM is to recognise the potential supply chain uncertainties and prevent the uncertainties with appropriate action. SCRM is made of four basic categories; risk sources, risk consequences, risk drivers, and risk mitigation strategies. However, this study only focuses on risk mitigation strategies that should be implemented by SME to overcome challenges that they faced.

In fact, there are still lots of companies that have not establish a structured supply chain risk management and mitigation system (Christopher, Mena, Khan \& Yurt, 2011) and unaware of supply chain disruption risk management (Johnson \& Nagarur, 2012). The area of SCRM is essential for Malaysian SMEs to help them sustain their business and overcome current risks and challenges. Besides, Klonowski (2012) stated that SCRM study is more apparent to the Small and Medium-sized Enterprises (SMEs) as the risk of technological change and innovation is imperative to SMEs, which plays a very important role in fostering economic growth of the country. In accordance with the main objective of SCRM of minimising the uncertainty situation arises and to contribute new ways of handling vulnerabilities in the supply chain, this study will identify the benefits of adapting risk mitigation strategies in the Malaysian SMEs. 


\section{Malaysian SME's}

The definition of SMEs is diverse across the countries and in Malaysia, it is based on two factors, which are the annual sales turnover and full-time employees (Hashim, 2011). SME has been recognised as an engine for future growth. This can be seen from the benefits that SME has brought to the country, such as providing employment, increasing income, and fostering growth (National SME Development Council, 2012). However, the business world nowadays faced with rapid changes in terms of customer demand, product lifecycle, technology, socio-cultural and market structure, which affect the SMEs' profitability and business growth.

\section{The Performance of Malaysian SME's}

According to National SME Development Council (2012), SMEs represent $99.2 \%$ of the total business establishment in Malaysia. However, SMEs' contribution to the economy is only about $32 \%$ of the Gross Domestic Product (GDP), $59 \%$ of employment and $19 \%$ of the total exports. Even though they represent the majority of business establishment in the country, their total contribution to the country's economy are still considered small compared to larger companies. Furthermore, Malaysian SME contributions towards the country's GDP, employment and export are comparatively low among Southeast Asian countries (OECD, 2013) as depicted in Figure 1.1. Wan Hooi (2014) has stated the difference between Malaysia, Singapore and United States, SME in Singapore are four time more productive, while United States are seven-times more productive than Malaysia.

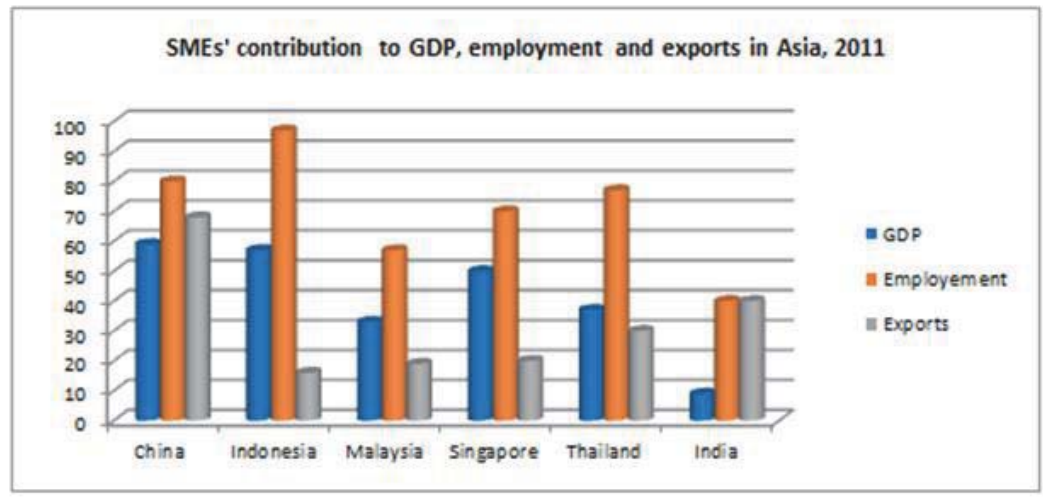

Figure 1.1 SME's contribution to GDP, employment and export in Asia, 2011.

Sources: Economic Outlook for Southeast Asia, China and India 2014: Beyond the Middle-Income Trap - OECD (2013).

In view of their significant role in contributing to economic growth, SMEs encounter numerous challenges in handling their business. The challenges comes in various forms including innovation and technology adoption, access to financing, legal and regulatory environment, human capital development, market access, and infrastructure (National SME Development Council, 2012). Furthermore, these challenges may arise because of SMEs weaknesses such as low level of technological capability, ICT penetration, research development (Saleh \& Ndubisi, 2006), poor creditworthiness, and lack of collateral difficult to obtain external fund (Onyango \& Achieng, 2013), difficult to understand the legal matters (Samad, Abdullah, Jusoff, Mohamad \& Nair, 2010; Muhammad, Char, Yasoa' \& Hassan, 2010), having unskilled and inexperience worker, fail to read market opportunities, misinterpret the market demand (Ahmad \& Seet, 2009), and increasing logistic cost (Zuraimi, Yaacob \& Ibrahim, 2013). These have seen a negative impact on company's performance.

Furthermore, these challenges can be seen as risks to SMEs performance. This study believes that these risks could give direct effect on the SMEs' ability to continue operations, produce finished goods, market the products, and provide critical services to customers, which will then impact the performance of the company. These risks can affect company's performance in various ways, such as high cost, poor quality product, low profit margin, and difficulties to retain customer. The impact of these risks could be the reason of SMEs failure in Malaysia. As stated by Zainul (2013, January 18), the failure rate of SMEs in Malaysia is at $36 \%$ in 2012. Besides, National SME Development Council (2012) stated $30 \%$ of entrepreneurs are fear of failure to start a business. Moreover, Ismail, Spian and Tay (2012) emphasised 
the importance to study the reasons behind the high failure and low performance among Malaysian SMEs.

\section{The Importance of SCRM in Malaysian SME's}

There are still lots of companies that have not established a structured supply chain risk management and mitigation system (Christopher et al., 2011) and unaware of the supply chain disruption risk management (Johnson \& Nagarur, 2012). Johnson and Nagarur (2012) stated that the reason of organisational lack of performance in supply chain is due to lack of knowledge on disruption event.

In addition, there is a lack of knowledge in the application of SCM, especially SCRM in the context of SMEs. As stated by Sunjka and Emwanu (2013), SCRM should be studied more extensively in SMEs due to limited studies in this area. According to Rahman, Wasilan, Deros and Ghani (2011), SME lacks of SCM knowledge in terms of SCM benefits or which SCM is suitable to be implemented for their needs. In addition, they listed other several barriers of SCM in SMEs, which are lack of skilled personnel for SCM development, lack of power to influence others in the supply chain, lack of trust by other members in supply chain, and lack of infrastructure in terms of financial and technical to implement SCM system. In another study done by Meehan and Muir (2008), they categorised the ensuing issues at three levels when SCM is adapted in SME, namely individual (lack of skilled personnel in SCM), relational (lack of interest, power, and trust) and organisational (competing initiative and doubts of benefits).

However, the benefit of SCM cannot be denied, as SCM adds values to the stakeholders, reduces lead time delivery, reduces operation cost, as well as provides competitive advantages and financial improvement (Saadany, Jaber \& Bonney, 2011; Jain \& Benyoucef, 2008; Chan, Humphreys \& Lu, 2001; Du, 2007; Meepetchdee \& Shah, 2007; Khan \& Pillania, 2008; Whitten et al., 2012). Furthermore, it brings efficiency in stable circumstance and competency in handling vulnerabilities in unstable circumstances (Johnson \& Nagarur, 2012).

Nowadays, the business world is challenging and risks can be anywhere and because of that, SCRM should be developed to manage these risks and challenges. As SME is shown to be an engine of future growth, identifying sources and managing SMEs risks are crucial. Risk sources could bring a negative impact to company's performance; both on short-term or long-term performance. In light of the risks arise, it is essential for the company to have a strategy to overcome these risks and hopefully enhance the company's performance. In addition, there are several researchers who agreed that supply chain risk mitigation strategies could enhance the company's performance (Whitten, Green \& Zelbst, 2012; Wieland \& Wallenburg, 2012).

\section{Supply Chain Risk Management (SCRM)}

The study of SCRM is one of the interesting and important researches as it contributes to inspiration for new ways of handling vulnerability in the chain. In stable environment, it is easy to construct efficient supply chain. However, in the current business environment, it could be difficult to achieve efficiency due to high vulnerability. This reason leads to the increasing demand of SCRM in today's business world

Despite studies that have been done in the area, SCRM remains without specific definition (Ponomarov \& Holcomb, 2009), as well as lack of theoretical model and framework focusing on the area (Gaonkar \& Viswanadham, 2007). Brindley (2004, p. 80) viewed the functions of "SCRM is to collaborate with partners in a supply chain or on your own, apply risk management process tools to deal with risks and uncertainties caused by, or impacting on, logistics related activities or resources in the supply chain". Meanwhile, Carter and Rogers (2008) envisioned SCRM as the capability of an organisation to be aware of risk, and the ability to manage the risk in the supply chain amongst economic, environmental, and social.

Gaonkar and Viswanadham (2007) relate supply chain risk with the probabilities and consequence of a mismatch between supply and demand. Meanwhile, Jüttner et al. (2003) expressed that SCRM recognises the potential supply chain uncertainties and prevent the uncertainties with the appropriate action. SCRM investigates supply chain risk phenomena and provides models for the analysis of several types of supply chain risks that occur both in the supply and demand sides of supply chains. An effective SCRM process is reliable to enhance risk performance (Kern et al., 2012). Additionally, companies that are involved in SCM could gain more advantage and benefits compared to those that are moving on their own.

According to Manuj and Mentzer (2008), the process flow of supply chain risk management can be divided into five steps, which are risk identification, risk assessment and evaluation, selection of risk management strategies, implementation of strategy, and mitigation of supply chain risks. However in this study, the researcher will focus on risk 
mitigation strategies. The risk mitigation strategy can be implemented once the supply chain members identify the potential of risk occurrence, consider the consequences, and determine the probability (Tummala \& Schoenherr, 2011).

\section{Risk Mitigation Strategies}

The main objective of SCRM is to minimise any uncertainty situation that may arise in a supply chain, as well as provide appropriate solutions in order to handle and manage the situation effectively. In other words, the function of SCRM is to recognise the potential sources of risk and implement appropriate strategies to prevent the supply chain exposure to risk. Supply chain strategy can be generally classified into two types; either reactive or proactive to disruption (Johnson \& Nagarur, 2012; Ghadge et al., 2012). Proactive can be defined as preventive (Wieland \& Wallenburg, 2012) or recovery action (Ghadge et al., 2012), whereas reactive is defined as changes action (Wieland \& Wallenburg, 2013). Examples of proactive action are the planning of strategic inventory (Johnson \& Nagarur, 2012) and multiple sources of supply (Wieland \& Wallenburg, 2012). In contrast, for reactive action, it can be conducted with backup supplier (Johnson \& Nagarur, 2012) and postponement (Ghadge et al., 2012).

Supply chain risk may appear in various ways, and invariably an organisation will use both proactive and reactive plans in handling the disruption. Literature has suggested some strategies in handling the vulnerability of supply chain, such as finding key supplier in new product development (Mikkola \& Skjøtt-Larsen, 2006), broad spans of integration (Kannan \& Tan, 2010), information sharing and incentive alignment (Eyaa, Ntayi \& Namagembe, 2010; Wiengarten, Humphreys, Cao, Fynes \& McKittrick, 2010), joint decision making (Wiengarten et al., 2010), seeking global supplier (Christopher et al., 2011) hedging and speculation (Peiying et al., 2012), and trust and collaborative relationships (Faisal et al., 2006).

Despite the strategies that have been identified, there are several types of risk mitigation strategy for SCRM that can be applied in their practice. The list of risk mitigation strategies that can be applied include robustness (Wieland \& Wallenburg, 2012), resilient (Sheffi, 2005; Isotupa, Kelly \& Kleffner, 2004), lean strategy (Carvalho et al., 2011), agile (Masson, Iosif, MacKerron \& Fernie, 2007; Charles et al., 2010), adaptability (Whitten et al., 2012), and flexible (Skipper \& Hanna, 2009).

For supply chain risk mitigation strategies, this study will only examine the strategies claimed by Wieland and Wallenburg (2012) on the importance of improving company performance, which are robustness and agility. In addition, these two strategies have been proved to be important in improving performance (Yang \& Liu, 2012; Wieland \& Wallenburg, 2012). This study will test the relationship between these two strategies and organisational performance. This leads to the following hypothesis:

$\mathrm{H} 1$ : There is a significant positive relationship between risk mitigation strategies and company performance.

\section{Methodology}

This study targets Malaysian manufacturing sectors among small to medium sized companies as the population. The reason of choosing manufacturing sectors is because these sectors are expected to contribute around RM120 billion or 50 percent of the total production by 2020 (Saleh \& Ndubisi, 2006). In this study, a questionnaire will be used to collect data on relevant factors in Malaysian manufacturing. Data was collected through survey questionnaire and the respondents consist of SMEs located in Peninsular Malaysia. The questionnaire consists of three sections, which are risk mitigation strategies, company performance, and demographic background (respondent profile and company profile). The respondents are the owner, director or manager of Malaysian manufacturing SMEs that have experience in operating companies operation. The population frame of this study is companies that are registered with SME Corporation Malaysia. This study uses a list of companies from SME Corporation Malaysia because it is a one-stop agency for the overall coordination of SME policy formulation and evaluation of SME development programs in all sectors. 500 questionnaires have been distributed, but only 153 were usable. Data analysis was conducted using SPSS 20.

\section{Results}

The majority of the respondent in the study, that is $91(59.5 \%)$, were males while the remaining $62(40.5 \%)$ were females. The respondent consist of 66 (43.1\%) of owner, 30 (19.6\%) of director and 57 (37.3\%) of manager. Among responding companies, $32.7 \%$ are sole proprietor, $25.5 \%$ partnership, and $41.8 \%$ limited companies. As indicated in Table 1.1, majority of the responding are from small companies, followed by micro companies and medium companies. 
Table 1.1 Demographic Profile of the Respondent

\begin{tabular}{|c|c|c|}
\hline & Frequency & Percentage \\
\hline \multicolumn{3}{|l|}{ Full time өmployөөs } \\
\hline Less than 5 & 55 & $35.9 \%$ \\
\hline $5-74$ & 85 & $55.6 \%$ \\
\hline $75-200$ & 12 & $7.8 \%$ \\
\hline More than 200 & 0 & $0 \%$ \\
\hline Missing & 1 & $0.7 \%$ \\
\hline $\begin{array}{l}\text { Average annual sales } \\
\text { Less than RM 300,000 }\end{array}$ & \\
\hline \multicolumn{3}{|c|}{$\begin{array}{l}\text { Less than RM } 300,000 \\
\text { Between } R M 300,000 \text { and less than }\end{array}$} \\
\hline & 84 & $54.9 \%$ \\
\hline \multicolumn{3}{|c|}{ Between $\mathrm{RM} 15 \mathrm{~m}$ - on and less } \\
\hline than RM 50 milion & 12 & $7.8 \%$ \\
\hline More than RM 50 milion & 0 & $0 \%$ \\
\hline Missing & 1 & $0.7 \%$ \\
\hline
\end{tabular}

The hypothesis of this study has been tested using simple regression analysis, due to have only one independent variable and only single predictor variable. The data analysis shows, there is a significant relationship between risk mitigation strategies and company performance whereby the significance value is $(p=.000)$ with the $F$ value is equal to 51.216. According to the result, $\mathrm{R}^{2}=.253$. The research model explains $25.3 \%$ of the total variance in risk mitigation strategies contributed to the company performance. The value of $t$ risk mitigation strategies relationship in coefficient is 7.157 and the significant value is $(p=.000)$. This shows that the between risk mitigation strategies adopted by the SMEs and their company performance. As indicated in Table 1.2, the value of constant is .134, which describes there is other factor that effect to the company performance. Therefore, risk mitigation strategies influenced the company performance with the value of .484 .

Table 1.2 Relationship between company performance with risk mitigation strategies

\begin{tabular}{|c|c|c|c|c|c|}
\hline \multirow{2}{*}{ Model } & \multicolumn{2}{|c|}{ Unstandardized Coefficients } & Standardized Coefficients & \multirow{2}{*}{$\mathrm{t}$} & \multirow{2}{*}{ Sig. } \\
\hline & $B$ & Std. Error & Beta & & \\
\hline (Constant) & .134 & .054 & & 2.464 & .015 \\
\hline Risk mitigation & .484 & .068 & .503 & 7.157 & .000 \\
\hline
\end{tabular}

\section{Discussion}

How can a company create its competitive advantages to maintain and enhance in the current dynamic business environment? The result demonstrates the importance of companies in implementation of risk mitigation strategies in their business practice can bring ways to help the company to prevent risks from occurring, which leads improvement in their performance. This study suggests that risk mitigation strategies have a positive significant relationship with company performance. In the past studies, there are several researchers suggested that organisations shall adapt to mix risk mitigation strategies to overcome the issues efficiently (Wieland \& Wallenburg, 2012; Wieland \& Wallenburg, 2013; Whitten et al., 2012). In line with that, this study adapts the agility and robustness as a risk mitigation strategy in improving the performance of SME's. The finding was parallel with recent articles, that justified these risk mitigation strategies (agility and robustness) has a positive significant in improving performance (Wieland \& Wallenburg, 2012). They emphasize agility is a particularly effective strategy in the case of high customer-side risks, while robustness is precondition in handling supplier-side risks.

By logically, this can be seen when the company attempt to emphasize on the risk mitigation strategy in reducing the probability of the risk occurs, it is same as company are trying to provide a beneficial impact on company performance. However, it cannot be denied there are a lots of risk mitigation strategy for SCRM that can be applied in 
their practice. Each of risk mitigation strategy has their own distinctive benefits and target. The importance is when selecting the strategy, an organisation must refer to the mutual goals agreed to ensure that all members' interest is considered and well maintained.

\section{Limitations and Further Research}

The scope of this study is to explore the bodies of knowledge pertaining to SCRM practice and gaining company performance. This area is essential for Malaysian SMEs to help them sustain their business and overcome current challenges. Since the study of SCRM is constantly growing, the researcher is interested to explore the effect of SCRM in SMEs. These areas are critical to enhance the performance of Malaysian SMEs since we all know SME is an independent and small enterprise that lacks of firm's size, number of workers, and size of return income. However, there are several limitation mark in this study and also suggest some direction for additional research.

The first limitation of this study is to simply test the relationship between risk mitigation strategies and performance, instead of testing the full process of SCRM. The additional research is needed by taking consideration of risk sources and identification risk before proceed to risk mitigation strategies. This research can be extending by defining the relationship between the sources of risks, risk mitigation strategies, and organisational performance among the Malaysian manufacturing SMEs. For instance, according to National SME Development Council (2012), SME are facing several challenges comes in various forms including innovation and technology adoption, access to financing, legal and regulatory environment, human capital development, market access, and infrastructure, which can affect them to improve their performance. The future research can be investigate the relationship between these challenges stated with risk mitigation strategies and company performance. Whether risk mitigation strategies could handle these challenges in improving SME's performance.

The second limitation, this study is classifying SCRM in the Malaysian Manufacturing SMEs, instead of introducing SCRM in a global framework. This is because in comparison to other larger businesses, SMEs have many shortcomings including small size, short capital, and reliance on government support. According to Peck et al. (2003), the requirement of SMEs for SCRM approach differs significantly from the larger businesses. Moreover, this research is carried out in Malaysia, thus might be not suitable to other countries for generalization. There are differences on the types of supply chain risks such as economy condition, government intervention, and environment. Besides, the samples from the manufacturing industry make the findings more specific to a particular industry. In the future, in order to study SCRM effectively, the study proposes an investigation for larger samples, as well as from other developing countries.

\section{References}

Ahmad, N. H., \& Seet, P. S. (2009). Dissecting behaviours associated with business failure: A qualitative study of SME owners in Malaysia and Australia. Asian Social Science, 5(9): 98-104.

Brindley, C. (Ed.). (2004). Supply Chain Risk. USA: Ashgate Publishing Limited.

Carter, C. R., \& Rogers, D. S. (2008). A framework of sustainable supply chain management: Moving toward new theory. International Journal of Physical Distribution \& Logistics Management, 38(5): 360-387.

Carvalho, H., Duarte, S., \& Machado, V. C. (2011). Lean, agile, resilient and green: Divergencies and synergies. International Journal of Lean Six Sigma, 2(2): 151-179.

Chan, F., Humphreys, P., \& Lu, T. (2001). Order release mechanisms in supply chain management: A simulation approach. International Journal of Physical Distribution \& Logistics Management, 31(2): 124-139.

Charles, A., Lauras, M., \& Wassenhove, L. V. (2010). A model to define and assess the agility of supply chains: Building on humanitarian experience. International Journal of Physical Distribution \& Logistics Management, 40(8/9): 722-741.

Christopher, M., Mena, C., Khan, O., \& Yurt, O. (2011). Approaches to managing global sourcing risk. Supply Chain Management: An International Journal, 16(2): 67-81.

Department of Statistics Malaysia. (2011). Economic Census 2011: Profile of small and medium enterprise. Retrieved from http://www.statistics.gov.my/portal/index.php?option=com_content\&view=article\&id=1721\&ltemid=111\&lang=en

Du, L. (2007). Acquiring competitive advantage in industry through supply chain integration: A case study of Yue Yuen Industrial Holdings Ltd. Journal of Enterprise Information Management, 20(5): 527 - 543.

Eyaa, S., Ntayi, J. M., \& Namagembe, S. (2010). Collaborative relationships and SME supply chain performance. World Journal of Enterprenuership, Management and Sustainable Developmnet, 6(3): 233-245.

Faisal, M. N., Banwet, D., \& Shankar, R. (2006). Mapping supply chains on risk and customer sensitivity dimensions. Industrial Management \& Data Systems, 106(6): 878-895.

Gaonkar, R. S., \& Viswanadham, N. (2007). Analytical Framework for the Management of Risk in Supply Chains. IEEE Transactions On Automation Science And Engineering, 4(2): 265-273. 
Ghadge, A., Dani, S., \& Kalawsky, R. (2012). Supply Chain Risk Management: Present and Future Scope. The International Journal of Logistics Management , 23(3).

Ismail, I., Spian, R., \& Tay, G. K. (2012). Entrepreneurial motivation linking entrepreneurial motivation, related experience, environment hostility with financial success . International Journal of Academic Research in Accounting, Finance and Management Sciences, 2(1): $150-161$.

Isotupa, K. P. S., Kelly, M., \& Kleffner. A. (2004). Building Resilient Supply Chains using Supply Chain and Traditional Risk Management and Insurance Techniques.

Jain, V., \& Benyoucef, L. (2008). Managing long supply chain networks: Some emerging issues and challenges . Journal of Manufacturing Technology Management, 19(4): 469-496.

Johnson, A. R., \& Nagarur, N. (2012). A discussion on supply chain robustness and resiliency. Industrial and Systems Engineering Research Conference.

Jüttner, U., Peck, H., \& Christopher, M. (2003). Supply Chain Risk Management: Outlining an agendafor future research. International Journal of Logistics : Research \& Applications, 6(4): 197-210.

Kannan, V. R., \& Tan, K. C. (2010). Supply chain integration: cluster analysis of the impact of span of integration. Supply Chain Management: An International Journal, 15(3): 207-215.

Kern, D., Moser, R., Hartmann, E., \& Moder, M. (2012). Supply risk management: Model development and empirical analysis. International Journal of Physical Distribution \& Logistics Management, 42(1): 60-82.

Khan, A., \& Pillania, R. K. (2008). Strategic sourcing for supply chain agility and firms' performance: A study of Indian manufacturing sector. Management Decision, 46(10): 1508-1530.

Manuj, I., \& Mentzer, J. T. (2008). Global supply chain risk management strategies. International Journal of Physical Distribution \& Logistics Management, 38(3): $192-223$.

Masson, R., Iosif, L., MacKerron, G., \& Fernie, J. (2007). Managing complexity in agile global fashion industry supply chains. The International Journal of Logistics Management, 18(2): 238 - 254.

Meehan, J., \& Muir, L. (2008). SCM in Merseyside SMEs: Benefits and barriers. The TQM Journal, 20(3): 223-232.

Meepetchdee, Y., \& Shah, N. (2007). Logistical network design with robustness and complexity considerations. International Journal of Physical Distribution \& Logistics Management, 37(3): 201-222.

Mikkola, J. H., \& Skjøtt-Larsen, T. (2006). Platform management: Implication for new product development and supply chain managment. European Business Review, 18(3): 214-230

Muhammad, M. Z., Char, A. K., Yasoa', M. R., \& Hassan, Z. (2010). Small and medium enterprises (SMEs) competing in the global business environment: A case of Malaysia. International Business Research, 3(1): 66-75.

National SME Development Council. (2012). Summary SME Masterplan 2012-2020: Catalysing Growth and Income. Retrieved from http://www.smecorp.gov.my/vn2/node/190

OECD. (2013). Economic Outlook for Southeast Asia, China and India 2014: Beyond the Middle-Income Trap. Retrieved from http://www.keepeek.com/Digital-Asset-Management/oecd/development/economic-outlook-for-southeast-asia-china-and-india2014/smes-contribution-to-gdp-employment-and-exports-in-asia-2011-or-latest-year-available_saeo-2014-graph105-en\#page1

Onyango, K. A., \& Achieng, M. R. (2013). Financial constraints of small and medium enterprises: A case study of kisumu county, Kenya. International Journal of Marketing and Technology, 3(7): 241-252.

Peiying, Y., Jiafa, T., \& Chongjun, Y. (2012). A Case Study of Global Supply Chain Risk Management. Chinese Control and Decision Conference (CCDC), 1996- 2000.

Peck, H., Abley, J., Christopher, M., Haywood, M., Saw, R., Rutherford, C., \& Strathern, M. (2003). Creating Resilient Supply Chains: A Practical Guide.Centre for Logistics and Supply Chain Management, Cranfield School of Management.

Ponomarov, S. Y., \& Holcomb, M. C. (2009). Understanding the concept of supply chain resilience. The International Journal of Logistics Management, 20(1): 124-143.

Rahman, M. N. A., Wasilan, H., Deros, B. M., \& Ghani, J. A. (2011). Barriers of SCM in SMEs. Applied Mechanics and Materials, 44: 3997-4001.

Saadany, A. E., Jaber, M., \& Bonney, M. (2011). Environmental performance measures for supply chains. Management Research Review, 34(11): 1202-1221.

Saleh, A.S., \& Ndubisi, N. O. (2006). An evaluation of SME development in Malaysia. International Review of Business Research Papers, 2(1): 1-14.

Samad, N. A., Abdullah, Z., Jusoff, K., Mohamad, Z., \& Nair, G. K. (2010). Globalisation

Sustainability of Malaysian small and medium-sized enterprises (SMEs) through gaining competitive advantages. Interdisciplinary Journal of Contemporary Research in Business, 2(1): 399-413.

Sheffi, Y. (2005). Supply chain strategy: Building a resilient supply chain. Harvard Business Review, 1(8): 1-4.

Skipper, J. B., \& Hanna, J. B. (2009). Minimizing supply chain disruption risk through enhanced flexibility. International Journal of Physical Distribution \& Logistics Management, 39(5): 404-427.

Sunjka, B. P., \& Emwanu, B. (2013). A conceptual framework for the analysis of supply chain risk management in small and medium manufacturing enterprises in South Africa. SAllE25 Proceedings, South Africa.

Tummala, R., \& Schoenherr, T. (2011). Assessing and managing risks using the Supply Chain Risk Management Process (SCRMP). An International Journal, 16(6): 474-483. 
Wan Hooi, L., \& Sing Ngui, K. (2014). Enhancing organizational performance of Malaysian SMEs: The role of HRM and organizational learning capability. International Journal of Manpower, 35(7), 973-995.

Whitten, G. D., Green, K. W., Jr., \& Zelbst, P. J. (2012). Triple-A supply chain performance.International Journal of Operations \& Production Management, 32(1): 28-48.

Wieland, A., \& Wallenburg, C. M. (2012). Emerald Article: Dealing with supply chain risks: Linking risk management Pratices and Strategies to Performance. International Journal of Physical Distribution \& Logistics Management, 42(10): 1-24.

Wieland, A., \& Wallenburg, C. M. (2013). The influence of relational competencies on supply chain resilience: a relational view. International Journal of Physical Distribution \& Logistics Management, 43(4): 300-320.

Wiengarten, F., Humphreys, P., Cao, G., Fynes, B., \& McKittrick, A. (2010). Collaborative supply chain pratices and performance: exploring the key role of information quality. Supply Chain Management: An International Journal , 15/6: 463-43.

Yang, C., \& Liu, H.-M. (2012). Boosting firm performance via enterprise agility and network structure. Management Decision, 50(6):10221044.

Zainul, I. F. (2013, January 18). Malaysian entrepreneurs now more confident of success than ever before. The Star Online. Retrieved from http://www.thestar.com.my/story.aspx/?file=\%2f2013\%2f1\%2f18\%2fbusiness $\% 2 f 12592824 \&$ sec=business

Zuraimi, A. A., Yaacob, M. R., \& Ibrahim, M. D. (2013). Logistics development in Malaysia east coast region: Infrastructure, constraints and challenges. International Journal of Trade, Economics an Finance, 4(5): 325-330. 